\title{
STUDI PERSALINAN KALA IV PADA IBU BERSALIN YANG MELAKUKAN INISIASI MENYUSU DINI (IMD) DI RUANG MINA RUMAH SAKIT MUHAMMADIYAH TUBAN
}

\author{
Umu Qonitun¹, Fitri Novitasari² \\ ${ }^{1}$ Dosen Prodi DIII Kebidanan STIKES Nahdlatul Ulama Tuban \\ 2Mahasiswa Prodi DIII Kebidanan STIKES Nahdlatul Ulama Tuban \\ *hafizh.hak@gmail.com
}

DOI : 10.24252/jkesehatan.v11i1.4572

\begin{abstract}
Abstrak
Masa nifas merupakan hal penting untuk memantau kondisi ibu terutama pada 2 jam pasca melahirkan. Pendarahan post-partum menjadi salah satu penyebab AKI, jika tidak di tangani dengan tepat akan mengakibatkan syok karena banyak darah yang keluar. Berdasarkan data yang diperoleh di Rumah Sakit Muhammadiyah Tuban pada bulan Januari - Juni Tahun 2017 kejadian pendarahan adalah sebesar (15) orang. Ini di karenakan atonia uteri, ruptur perineum, dan tertinggalnya plasenta. Tujuan dari penelitian ini adalah untuk mengetahui studi persalinan kala IV pada ibu bersalin yang di lakukan Inisiasi Menyusu Dini. Penelitian ini menggunakan metode diskriptif dengan populasi 29 ibu bersalin yang dilakukan Inisiasi Menyusu Dini di Rumah Sakit Muhammadiyah Tuban. Penelitian ini menggunakan tehnik purposife sampling sehingga memperoleh besar sampel $29 \mathrm{ibu}$ bersalin. Variabel penelitiannya yaitu Tekanan Darah, Nadi, Tinggi Fundus Uteri (TFU), dan Kontraksi Uterus. Tehnik pengumpulan data dengan observasi langsung terhadap responden. Analisa data di proporsikan dalam bentuk presentase. Hasil penelitian dari 29 responden menunjukkan bahwa ibu bersalin yang dilakukan (IMD) hampir seluruhnya normal. Tekanan Darah normal sebanyak 29 orang (100\%), Nadi normal sebanyak 29 orang $(100 \%)$, TFU nomal sebanyak 29 orang $(100 \%)$, dan hanya Kontraksi Uterus yang hampir normal seluruhnya yaitu 27 orang $(93,10 \%)$. Dari hasil penelitian bahwa IMD dapat berpengaruh terhadap persalinan kala IV. Sehingga disarankan IMD dapat diterapkan pada persalinan untuk menekan terjadinya pendarahan post partum serta menekan AKI di Indonesia.
\end{abstract}

Kata Kunci : Persalinan Kala IV, Ibu Bersalin, Inisiasi Menyusui Dini

\section{Abstract}

The post-partum period is important thing to monitoring woman conditional, especially at 2 hours post-partum. Post-partum bleeding became one of cause mortality (AKI), if it doesn't handled appropriately will causes shock because it will be worst bleeding. Based on data obtained in Muhammadiyah Hospital of Tuban on January - July 2017 post-partum bleeding are 15 people, it cause of uterine atony, rupture perineum, and placenta loss. The purpose of this research to find out the overview of post-partum in stage IV of women giving birth which is initiated early breastfeeding. The research used descriptive method with population 29 woman giving birth which is initiated early breastfeeding in Muhammadiyah Hospital of Tuban. This research used technique purposive sampling that getting samples 29 woman maternity. The research variables are blood pressure, pulse, high fundus 
uteri (TFU), and urine contraction. Technique of data collection by direct observation with respondent, data analysis proportioned in percentage. The result of 29 respondents show that woman giving birth who are doing (IMD) almost entirely normal. Blood pressure which is normal as much as 29 people (100\%), pulse which is normal as much as 29 people (100\%), TFU which is normal as much as 29 people (100\%), and only urine contraction which is almost normal entirely there are 27 people (93,10\%). Based on the research result that (IMD) cause take effect for post-partum stage IV, so it suggested that IMD can applied in every childbirth to decrease incidence of post-partum bleeding and to decrease mortality in Indonesia.

Key words : Childbirth Stage IV, Woman Giving Birth, Initiated Early Breastfeeding

\section{PENDAHULUAN}

Hasil Survei Demografi dan Kesehatan Indonesia (SDKI) tahun 2015, angka kematian ibu di Indonesia masih tinggi sebesar 309 per 100.000 kelahiran hidup. Angka ini turun jika di bandingkan pada tahun 2012 yang hanya 359 per 100.000 kelahiran hidup. Target global SDGs (Sustainable Development Goals) tahun 2030 adalah menurunkan Angka Kematian Ibu (AKI) menjadi 70 per 100.000 kelahiran hidup.

Menurut Kementrian Kesehatan tahun 2010, tiga faktor utama penyebab kematian ibu melahirkan adalah Pendarahan (28\%), Eklampsia (24\%), dan Infeksi (11\%). Pada tahun 2013 penyebab kematian ibu di Indonesia akibat pendarahan sebanyak (30,3\%) (Kemenkes RI, 2016). Sedangkan di RS Muhammadiyah Tuban pada bulan Januari Juni Tahun 2017 angka kejadian pendarahan adalah sebesar (15) orang.

Pendarahan postpartum adalah kehilangan darah antara $500 \mathrm{ml}$ atau lebih selama bersalin ataupun masa nifas. Pendarahan post partum pada 24 jam pertama menyebabkan kematian sebesar $45 \%, 68 \%-73 \%$ dalam satu minggu setelah bayi lahir, dan $82 \%-88 \%$ dalam dua minggu setelah bayi lahir . Penyebab pendarahan postpartum yaitu 4T (Tonus, Tissu, Trauma, dan Trombin). Penyebab lain pendarahan post partum antara lain oleh plasenta previa, retensio plasenta, atonia uteri, inversio uteri, ruptur uteri, kehamilan ektopi, abortus, dan laserasi jalan lahir (Prawirohardjo, 2010).

Pendarahan post partum menjadi hal yang menakutkan sebab dalam beberapa kasus merupakan pendarahan yang hebat dalam waktu singkat sehingga ibu melahirkan mengalami syok dan menurunkan kesadaran akibat banyak darah yang keluar. Hal ini menyebabkan gangguan sirkulasi darah ke saluran tubuh dan dapat menyebabkan hipofolemik berat. Ataupun dalam kasus lain pendarahan yang perlahan-lahan secara terus menerus membuat ibu menjadi lemas dan syok hingga menyebabkan kematian

Departemen Kesehatan telah mengatasi kematian ibu melalui kebijakan Asuhan Persalinan Normal (APN) sesuai dengan pendekatan Making Pregnancy Safer (MPS) yang diprakarsai oleh WHO. Pendekatan ini bertujuan menurunkan angka kematian 
ibu melalui kegiatan peningkatan akses pemanfaatan pelayanan kesehatan ibu yang berkualitas kepala ibu hamil, bersalin dan nifas. Salah satu kegiatan yang di lakukan dalam melaksanakan Asuhan Persalinan Normal (APN) adalah Inisiasi Menyusu Dini (IMD). Program IMD didukung oleh pemerintah dalam bentuk Peraturan Pemerintah RI nomor 33 tahun 2012 pasal 9 tentang Pemberian Air Susu Ibu Eksklusif (Kemenkes RI, 2008).

IMD yaitu bayi mulai menyusu sendiri segera setelah lahir. Dengan meletakkan bayi baru lahir tengkurap di dada ibu dalam waktu minimal 1 jam hingga menimbulkan kontak kulit ibu dan kulit bayi sampai dapat menyusu sendiri, hentakan kepala bayi ke dada ibu, sentuhan tangan bayi di putting susu dan sekitarnya, emutan dan jilatan bayi pada putting ibu merangsang pengeluaran hormon oksitosin, dimana hormon oksitosin membantu uterus berkontraksi sehingga membantu mempercepat pelepasan dan pengeluaran ari-ari (placenta) dan menurunkan resiko pendarahan pasca persalinan serta mempercepat kembalinya uterus ke bentuk semula hormon oksitosin juga merangsang produksi hormon lain yang membuat ibu menjadi lebih rileks, lebih mencintai bayinya, meningkatkan ambang nyeri, dan perasaan sangat bahagia. (Sondakh, 2013).

Dari uraian di atas dapat dilihat bahwa sangat penting bagi ibu untuk menyusukan bayinya segera setelah lahir. Oleh karena itu penulis tertarik untuk meneliti sejauh mana Gambaran Persalinan Kala IV Pada Ibu Bersalin yang dilakukan Inisiasi Menyusu Dini (IMD) di Ruang Mina RS Muhammadiyah Tuban. Karena tempat tersebut telah melakukan IMD secara standar.

\section{METODOLOGI PENELITIAN}

Penelitian ini merupakan penelitian diskriptif. Variabel penelitiannya yaitu Tekanan Darah, Nadi, Tinggi Fundus Uteri (TFU), dan Kontraksi Uterus. Populasi pada penelitian ini berjumlah $29 \mathrm{ibu}$ bersalin. Sampel pada penelitian ini berjumlah 29 responden. Tehnik pengambilan sampel purposife sampling, memilih sampel dari populasi sesuai yang di kehendaki peneliti (Nursalam, 2008). Alat pengumpulan data pada penelitian ini adalah observasi langsung terhadap responden. Analisa data di proporsikan dalam bentuk presentase.

\section{HASIL DAN PEMBAHASAN}

Penelitian ini di lakukan di Ruang Mina RS Muhammadiyah Tuban. Pada penelitian ini yang di jadikan responden adalah seluruh ibu bersalin yang melakukan IMD.

\section{Umur Responden}

Distribusi data responden berdasarkan umur ibu bersalin yang melakukan IMD di Ruang Mina RS Muhammadiyah Tuban pada Agustus 2017 


\begin{tabular}{clcc}
\hline No & \multicolumn{1}{c}{ Umur } & $f$ & $\%$ \\
\hline 1 & $20-35$ tahun & 28 & 96,55 \\
2 & $<20$ tahun dan $>35$ & 1 & 3,45 \\
& $\begin{array}{l}\text { tahun } \\
\text { Jumlah }\end{array}$ & 29 & 100 \\
\hline
\end{tabular}

Sumber : Data Primer 2017 Mean : 26 tahun, Median : 25 tahun, Modus : 23 tahun.

Berdasarkan tabel 1 bahwa dari 29 responden di dapatkan sebagian besar responden berumur produktif 28 (96,55\%).

2. Tekanan Darah (TD) ibu bersalin yang melakukan IMD

Distribusi Kala IV (TD) 30 menit terakhir dalam 2 jam pasca persalinan yang melakukan IMD di Ruang Mina RS Muhammadiyah Tuban pada Agustus 2017

\begin{tabular}{|c|c|c|c|}
\hline No & $\begin{array}{l}\text { Kala IV } \\
\text { (TD) }\end{array}$ & $f$ & $\%$ \\
\hline 1 & Normal & 29 & 100 \\
\hline 2 & $\begin{array}{l}\text { Tidak } \\
\text { Normal }\end{array}$ & 0 & 0 \\
\hline & Jumlah & 29 & 100 \\
\hline
\end{tabular}

Berdasarkan tabel 2 menunjukkan bahwa Tekanan darah dari 29 ibu bersalin yang melakukan IMD normal seluruhnya $29(100 \%)$.

3. Nadi ibu bersalin yang melakukan IMD

Distribusi Kala IV (Nadi) 30 menit terakhir dalam 2 jam pasca persalinan yang melakukan IMD di Ruang Mina RS Muhammadiyah Tuban pada Agustus 2017

\begin{tabular}{clcc}
\hline No & Kala IV (Nadi) & $f$ & \% \\
\hline 1 & Normal & 29 & 100 \\
2 & Tidak Normal & 0 & 0 \\
\hline & Jumlah & 29 & 100 \\
\hline
\end{tabular}

Sumber: Data Primer 2017

Berdasarkan tabel 3 menunjukkan bahwa nadi dari 29 ibu bersalin yang melakukan IMD normal seluruhnya $29(100 \%)$. 
4. Kontraksi uterus ibu bersalin yang melakukan IMD

Distribusi Kala IV (Kontraksi Uterus) 30 menit terakhir dalam 2 jam pasca persalinan yang melakukan IMD di Ruang Mina RS Muhammadiyah Tuban pada Agustus 2017

\begin{tabular}{clcc}
\hline No & Kala IV (Kontraksi Uterus) & $f$ & $\mathbf{~}$ \\
\hline 1 & Normal & 27 & 93,10 \\
2 & Tidak Normal & 2 & 6,90 \\
\hline & Jumlah & 29 & 100 \\
\hline
\end{tabular}

Sumber: Data Primer 2017

Berdasarkan tabel 4 menunjukkan bahwa Kontraksi Uterus dari 29 ibu bersalin yang melakukan IMD sebagian besar yaitu seluruhnya $27(93,10 \%)$.

\section{PEMBAHASAN}

Persalinan Kala IV (TD) pada Ibu Bersalin yang melakukan IMD di Ruang Mina RS Muhammadiyah Tuban. Tekanan darah dari ibu bersalin yang melakukan IMD seluruhnya normal serta tidak ada satu pun Tekanan Darah ibu yang tidak normal. Tekanan darah merupakan tekanan yang terjadi pada pembuluh darah arteri ketika darah kita di pompa oleh jantung untuk di alirkan ke seluruh anggota tubuh. Umumnya orang dewasa memiliki tekanan darah normal di bawah 120/80 atau setara 110/70 mmHg. Pasca melahirkan pada ksus normal, tekanan darah biasanya tidak berubah (Nurasih, 2012). Tekanan darah pada kala IV jika tidak normal kemungkinan akan menimbulkan masalah. Perubahan tekanan darah menjadi lebih rendah pasca melahirkan dapat diakibatkan oleh pendarahan. Pemantauan tekanan darah dan nadi yang rutin pada kala IV adalah satu sarana mendeteksi syok akibat kehilangan darah yang berlebihan. Sedangkan tekanan darah tinggi setelah melahirkan merupakan tanda terjadinya pre eklamsia post partum. Namun demikian, hal tersebut jarang terjadi.

Salah satu manfaat IMD bagi ibu yaitu getaran cinta saat ibu dipeluk oleh suaminya maka akan merasakan ketenangan, merasa dilindungi, dan kuat secara psikis, ibu menjadi lebih tenang, memfasilitasi kelahiran plasenta, dan pengalihan rasa nyeri dan berbagai prosedur pasca persalinan lainnya, membantu ibu mengatasi stres terhadap berbagai rasa kurang nyaman, memberi efek relaksasi pada ibu setelah bayi selesai menyusu. Dan menstimulasi kontraksi uterus serta menurunkan resiko pendarahan pasca persalinan (Sondakh, 2013). Berdasarkan teori dan fakta maka dapat di lihat bahwa ibu bersalin yang melakukan IMD dapat mempengaruhi Tekanan Darah ibu menjadi normal karena manfaat IMD bagi ibu yaitu ibu menjadi lebih tenang, nyaman dan rileks sehingga tekanan darah ibu menjadi normal. Karena kecemasan akan memicu pelepasan hormon yang menyebabkan peningkatan denyut jantung dan menurunkan diameter pembuluh darah, yang dapat menyebabkan peningkatan 
tekanan darah. Sehingga IMD sangat berhubungan dan memberi manfaat bagi kala IV ibu bersalin.

Persalinan Kala IV (Nadi) pada Ibu Bersalin yang melakukan IMD di Ruang Mina RS Muhammadiyah Tuban. Nadi dari ibu bersalin yang melakukan IMD seluruhnya normal, serta tidak ada satu pun Nadi ibu yang tidak normal. Nadi yaitu pembuluh darah yang berotot yang membawa darah dari jantung. Denyut nadi normal pada orang dewasa 60-80 kali permenit. Pemantauan tekanan darah dan nadi pada kala IV ini adalah untuk mendeteksi syok akibat kehilangan darah yang berlebihan (Saleha, 2009). Pada masa nifas umumnya denyut nadi stabil dibandingkan dengan suhu tubuh, sedangkan pernafasan akan lebih sedikit meningkat setelah partus kembali seperti semula. Denyut nadi ini dikaitkan dengan tekanan darah ibu, jika tekanan darah ibu rendah dan nadi cepat ini menandakan bahwa ibu terlalu banyak kehilangan darah tetapi jika ibu dengan nadi normal dan tekanan darahnya rendah mungkin tidak akan terjadi masalah. Salah satu manfaat IMD bagi ibu yaitu getaran cinta saat ibu di peluk oleh suaminya maka akan merasakan ketenangan, merasa dilindungi, dan kuat secara psikis, ibu menjadi lebih tenang, memfasilitasi kelahiran plasenta, dan pengalihan rasa nyeri dan berbagai prosedur pasca persalinan lainnya, membantu ibu mengatasi stres terhadap berbagai rasa kurang nyaman, memberi efek relaksasi pada ibu setelah bayi selesai menyusu. Dan menstimulasi kontraksi uterus serta menurunkan resiko pendarahan pasca persalinan (Sondakh, 2013). Berdasarkan teori dan fakta kenyataan maka dapat di lihat bahwa jika ibu bersalin yang melakukan IMD dapat mempengaruhi Nadi ibu menjadi normal karena manfaat IMD bagi ibu salah satunya yaitu membantu ibu mengatasi stres terhadap berbagai rasa kurang nyaman dan memberi efek relaksasi pada ibu setelah bayi selesai menyusu sehingga ibu merasa lebih tenang sehingga nadi ibu menjadi normal atau stabil. Maka dapat disimpulkan bahwa IMD sangat berhubungan dan memberi manfaat bagi kala IV ibu bersalin.

Persalinan Kala IV (TFU) pada Ibu Bersalin yang melakukan IMD di Ruang Mina RS Muhammadiyah Tuban. TFU dari ibu bersalin yang di lakukan IMD seluruhnya normal, serta tidak ada satu pun TFU ibu yang tidak normal. Setelah plasenta lahir uterus nomalnya di bawah umbilikalis, jika uterus berada di atas umbilikus hal ini menandakan adanya darah di dalam dan harus segera dikeluarkan dan ditangani (Sondakh, 2013). Pada kala IV uterus yang berada di atas umbilikus dan bergeser cenderung menandakan kandung kemih penuh. Manfaat IMD bagi ibu yaitu mengeluarkan hormon oksitiosin yang dapat membantu merangsang kontraksi uterus sehingga dapat mengembalikan uterus seperti semula. Berdasarkan teori dan fakta kenyataan maka dapat di lihat bahwa jika ibu bersalin yang melakukan IMD dapat mempengaruhi TFU menjadi normal karena manfaat IMD bagi ibu salah satunya adalah mengeluarkan hormon oksitosin yang dapat mempercepat proses involusi uterus. Proses involusi uterus merupakan pengelupasan situs plasenta sebagaimana diperlihatkan oleh warna dan lokia serta ukuran uterus yang semakin hari semakin mengecil sehingga menjadi (normal). Proses involusi tersebut dapat berjalan dengan 
baik dan dapat dipercepat prosesnya bila ibu menyusui bayinya. Maka dapat disimpulkan bahwa IMD sangat berhubungan dan memberi manfaat bagi kala IV ibu bersalin.

Persalinan Kala IV (Kontraksi Uterus) pada Ibu Bersalin yang melakukan IMD di Ruang Mina RS Muhammadiyah Tuban. Kontraksi Uterus dari ibu bersalin yang melakukan IMD sebagian besar yaitu hampir seluruhnya normal, sedangkan yang tidak normal hanya sebagian kecil saja. Kontraksi uterus yaitu pembuluh darah yang berada di antara anyaman otot uterus akan terjepit. Proses ini akan menghentikan pendarahan pasca persalinan serta mempercepat proses involusi uterus. Uterus yang berada di atas umbilikus dan bergeser cenderung menandakan kandung kemih penuh. Uterus yang berkontraksi normal harus keras ketika di sentuh. Jika uterus lembek nenandakan bahwa kontraksi uterus tidak normal (Saleha, 2009). Menyusui merupakan metode efektif untuk meningkatkan tonus uteri selain itu dapat di lakukan dengan cara mempertahankan masase pada uterus sehingga dapat mengurangi pendarahan. Berdasarkan teori dan fakta kenyataan maka dapat dilihat bahwa jika ibu bersalin yang melakukan IMD dapat mempengaruhi kontraksi uterus jika kontraksi uterus tidak baik maka uterus terasa lembek, lakukan masase uterus dan seluruhnya ibu bersalin yang melakukan IMD yaitu sebagian kecil saja yang kontraksi uterusnya lembek hal ini dikarenakan kurangnya pengetahuan ibu tentang massase uterus jika uterus ibu lembek. Dan setelah di lakukan masase uterus oleh petugas maka uterus ibu dapat berkontraksi dengan baik (keras). Maka dapat di simpulkan bahwa IMD sangat berhubungan dan memberi manfaat bagi kala IV ibu bersalin.

\section{KESIMPULAN}

Setelah mengetahui dan mempelajari hasil penelitian ini maka akan di uraikan tentang kesimpulan dari hasil penelitian dan gambaran Persalinan Kala IV Pada Ibu Bersalin yang melakukan Inisiasi Menyusu Dini (IMD) di Ruang Mina RS Muhammadiyah Tuban

1. Seluruhnya Tekanan Darah pada ibu bersalin yang melakukan IMD di Ruang Mina RS Muhammadiyah Tuban pada Agustus 2017 kategori normal.

2. Seluruhnya Nadi pada ibu bersalin yang melakukan IMD di Ruang Mina RS Muhammadiyah Tuban pada Agustus 2017 dalam kategori normal.

3. Seluruhnya TFU pada ibu bersalin yang melakukan IMD di Ruang Mina RS Muhammadiyah Tuban pada Agustus 2017 dalam kategori normal.

4. Hampir seluruhnya Kontraksi Uterus pada ibu bersalin yang melakukan IMD di Ruang Mina RS Muhammadiyah Tuban pada Agustus 2017dalam kategori normal.

\section{DAFTAR PUSTAKA}

Bari, S. A. (2007). Ilmu Bedah Kebidanan. Jakarta : Bina Pustaka. 
Depkes, RI. (2015). Profil Kesehatan Indonesia Rakorpop Kementerian Kesehatan RI Jakarta, 1 Desember 2015. Jakarta : Depkes.

Eka,W. E. (2014). Modul Menyusui yang Benar. Tuban: STIKES NU TUBAN.

Kemenkes, RI. (2016). Profik Kesehatan. Jakarta : Depkes.

Maryunani, A. (2009). Asuhan pada Ibu dalam Masa Nifas. Jakarta: TIM.

Meiliya, E, dkk. (2009). Buku Saku Kebidanan. Jakarta : EGC.

Nurasiah, A, dkk. (2012). Asuhan Persalinan Normal Bagi Bidan. Refika Aditama: Bandung.

Nursalam. (2008). Konsep dan Penerapan Metodologi Penelitian Ilmu Keperawatan. Jakarta : Salemba Medika.

Prawirohardjo, S. (2014). Ilmu Kebidanan. Jakarta : PT Bina Pustaka.

Roesli, U. (2007). Inisiasi Menyusu Dini Plus ASI Ekslusif Cetakan I. Jakarta : Pustaka Bunda.

Simkin, P, dkk. (2007). Panduan Lengkap Kehamilan, Melahirkan, E Bayi. Jakarta : Surya Satyanegara.

Saleha, S. (2009). Asuhan Kebidanan Pada Masa Nifas. Jakarta: Salemba Medika.

Sondakh, J.J.S. (2013). Asuhan Kebidanan Persalinan \& Bayi Baru Lahir. Jakarta : Erlangga.

Sugiyono. (2008). Metode Penelitian Kuantitatif Kualitatif Dan R E D. Bandung : Alfabeta.

Varney, H, dkk. (2007). Buku Ajar Asuhan Kebidanan. Jakarta : EGC.

Walyani, E. S. (2015). Asuhan Kebidanan pada Kehamilan. Yogyakarta: Pustaka Barupess. 